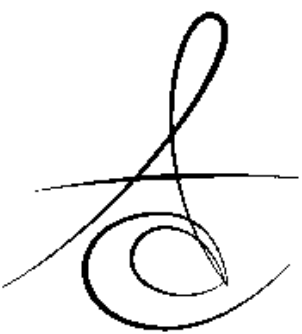

\title{
BİFOSFONAT KULLANIMINA BAĞLI ÇENE KEMİKLERİNDE GÖRÜLEN OSTEONEKROZ VAKALARININ MEDİKAL VE CERRAHİ TEDAVİLERİ SONRASI UZUN DÖNEM TAKİPLERİ
}

\author{
LONG TERM FOLLOW UP OF PATIENTS WITH BISPHOSPHONATE RELATED \\ OSTEONECROSIS OF THE JAWS AFTER MEDICAL AND SURGICAL TREATMENT
}

\author{
Dr. Öğr. Üyesi Necip Fazıl ERDEM*
}

Arş Gör. Zeynep GÜMÜŞER*

Makale Kodu/Article code: 3575

Makale Gönderilme tarihi: 16.02 .2018

Kabul Tarihi: 13.07.2018

\section{ÖZ}

Amaç: Bu çalışman amacı bifosfonata bağlı çene kemiğinin osteonekrozu (Bisphosphonate Related Osteonecrosis of the Jaws [BRONJ]) tanısı konmuş hastaların, yapılan medikal ve cerrahi tedavileri sonrasında tedavilerinin başarısını görmek ve uzun dönem takibin önemini vurgulamaktır.

Gereç ve Yöntem: BRONJ tanısı konulmuş, altısı kadın ikisi erkek olmak üzere 8 hastanın ilaç ve cerrahi tedavileri ve uzun dönem klinik ve radyolojik takip sonuçları değerlendirilmiştir. Ruggiero ve arkadaşlarının oluşturduğu evrelendirmeye göre vakalar evrelendirilmiş ve tedavileri yapılmıştır. Hastaların üçü osteoporoz (biri intravenöz, ikisi oral yoldan), kalan beşi malignite (intravenöz yoldan) nedeneniyle bifosfonat kullanmaktadır.

Bulgular: Hastalar 8 ila 43 ay arasında değişen, ortalama 23.8 aylık süreyle bifosfonat grubu ilaç almışlardır. Hastaların ortalama yaşları 61.2 ve tedavi sonrası ortalama takip süreleri ise 12.5 aydır. , 8 vakanın beşi evre 3, diğer üçü ise evre 2 olarak değerlendirilmiştir. Evre 3 hastaların hiçbirinde, medikal ve cerrahi tedavi sonrası belirtilen takip süresince klinik ve radyolojik olarak BRONJ rekürrensi görülmemiştir. Evre 2 vakalarda ise ilaç tedavisi sonrası hastalık semptomatik olarak kontrol altına alınmıştır.

Sonuç : Sonuç olarak uygulanan bu tedavi protokolü ve bu çalışmaya dahil edilen vakalardan elde edilen veriler, cerrahi tedavinin gerektiğinde uygun zamanda yapılmasının önemini güçlendirmiştir. Ayrıca hiperbarik oksijen tedavisinin BRONJ vakalarında yardımcı tedavi yöntemlerinden biri olarak düşünülebileceği söylenebilir. Bifosfonat kullanım nedenleri hastaların cerrahi ya da medikal yolla tedavi edilmelerinde direkt olarak etkili olmamıştır.

Anahtar kelimeler: Bifosfonat, çene osteonekrozu, hiperbarik oksijen tedavisi

\begin{abstract}
Aim: The aim of this study is to observe the success of medical and surgical treatment of the patients who have been diagnosed as the bisphosphonate related osteonecrosis of the jaws (BRONJ) and emphasize the importance of long term follow up of these patients.

Material and Methods: The medical and surgical treatments and long term clinical and radiological follow ups of 8 BRONJ cases, of whom 6 women and 2 men, were evaluated in this study. All cases were staged according to a staging system that was implemented by Ruggiero et al. and treated accordingly. Three of the patients (one intravenously and two orally) were on bisphosphonate due to osteoporosis and five of them (intravenously) due to malignant diseases.

Results: Patients were on bisphosphonate for an interval of 8 to 43 months with a mean time period of 23.8 months. The mean age of the patients was 61.2 and the mean postoperative follow up time was 12.5 months. According to Ruggiero et al BRONJ staging, 5 of 8 cases were at stage- 3 and the rest of them were at stage-2. None of the stage-3 cases that were treated medically and surgically showed any BRONJ recurrence clinically and radiographically during their follow up periods. Also, all three stage-2 BRONJ cases were kept under control symptomatically with medical treatment protocol.

Conclusion: As a conclusion, the treatment protocol and outcome data of this study on BRONJ cases have reinforced the importance of surgical treatment that is performed at an appropriate time. Also it is possible to emphasize that hyperbaric oxygen treatment can be an adjuvant treatment method for BRONJ cases. The reason of bisphosphonate usage of these patients did not directly have any effect on either they treated surgically or medically.

Key Words: Bisphosphonate, jaw osteonecrosis, hyperbaric oxygen treatment
\end{abstract}

* Marmara Üniversitesi Diş Hekimliği Fakültesi Ağız Diş Çene Cerrahisi Anabilim Dalı, İstanbul. 


\section{GİRİş}

Günümüzde ilaca bağlı çene kemiğinin osteonekrozu (Medication-Related Osteonecrosis of the Jaw [MRONJ]) Ağız, Diş ve Çene Cerrahisinde sıklıkla karşılaşılan bir hastalıktır. MRONJ'a neden olan iki grup ilaç bulunmaktadır. Bunlar bifosfonatlar ve antianjiogenik ilaçlardır. Bu ilaçları kullanan ve baş boyun bölgesinden radyoterapi almayan hastalarda çene kemiklerinde 8 haftadan daha uzun süren ekspoze kemik varlığı durumunda MRONJ tanısı konur $^{1}$. Antianjiogenik ilaçlar, onkolojide malign tümörlerin damarlanmasını engellemek amaçlı kullanılırlar ve vascular endothelial growth factor'ü (VEGF) baskılayarak etki ederler ${ }^{2,3}$. Bifosfonatlar ise osteoporoz, malign tümörlerin osteolitik kemik metastazları, malign tümörlerin neden olduğu hiperkalsemi ve Paget's hastalığı varlığında kullanılırlar $^{4-8}$. Bu grup ilaçlar ise kemik osteoklastik aktivitesini ve kemik döngüsünü baskılayarak etki gösterirler ${ }^{9}$. Her iki grup ilacın faydalarının yanında, çene kemiklerinde osteonekroza neden olmak gibi kötü bir yan etkileri de vardır. Antianjiogenik ilaçlar VEGF'ün baskılanması nedeniyle; bifosfonatlar ise osteoklast aktivitesinin baskılanması nedeniyle çene kemiklerinde osteonekroza neden olabilirler. İlk bifosfonata bağlı çene kemiğinin osteonekrozu (Bisphosphonate Related Osteonecrosis of the Jaws [BRONJ]) tanısı 2003 yılında Marx tarafından 36 yaşındaki bir hastaya konmuştur ${ }^{10}$. Gün geçtikçe bu grup ilaçların kullanımı ve buna bağlı olarak gelişen çene kemiklerinde osteonekrozun görülme sıklığı artmıştır. Bu hastalarda çenelerde ekspoze ve nekrotik kemik spontan gelişebileceği gibi, yapılan basit bir dentoalveolar işlem sonrası da görülebilmektedir ${ }^{11}$. Dolayısıyla tüm diş hekimlerinin bu grup hastalara tedavi planı yaparken oluşabilecek komplikasyonları çok iyi değerlendirmeleri gerekir ${ }^{12,13}$. Eğer bu komplikasyon oluşmuşsa da, tanı konulup hastalığın evrelendirilmesi ve doğru tedavi planının yapılması çok önemlidir.

Osteoklast gelişiminde ve aktivasyonunda receptor activator of nuclear factor-kb ligand (RANKL), receptor activator of nuclear factor-kb (RANK) ve osteoprotegerin (OPG) adlı üç önemli protein görev almaktadır $^{14-19}$. RANKL/RANK bağlantısı osteoklastları aktive ederken, RANKL/OPG bağlantısı osteoklast aktivitesini baskılar ${ }^{19,20}$. Yapılan birçok in vivo ve in vitro çalışmalara göre malign tümör hücrelerinin ürettiği prostoglandin $E_{2},\left(P G E_{2}\right)$ gibi prostaglandinler ve interleukin-6 (IL-6), interleukin-11( IL-11), tumor necrosis factor-a (TNF-a ), parathyroid hormone related protein (PTHrP) gibi sitokinler kanser hücrelerinin çoğalmasında ve osteoklastogenez üzerine direkt etkilidirler ${ }^{21-26}$. Özellikle PTHrP'in malign tümör vakalarında kanda hiperkalsemiye neden olduğu; hiperkalseminin de tümörün kemik invazyonunu hızlandırdığı bildirilmiştir ${ }^{27}$. Tümör hücrelerinden salgılanan PTHrP, stromal hücrelerdeki RANKL'ın aktive olmasını, RANKL ise osteoklast progenitör hücrelerinin yüzeyindeki RANK'nin uyarılmasını tetikler ve sonuç olarak RANK sinyali osteoklastogenezi başlatır. Bifosfonatlar RANKL-RANK bağlantısını bloke edip osteoklastogenezi baskılayarak etki gösterirler. ${ }^{8} \mathrm{Bu}$ sinyaller oksijene karşı hassastırlar. Hiperbarik oksijen tedavisinin bu sinyallerin aktivasyonunu etkileyebileceği düşünülmektedir ve BRONJ tedavisinde kullanılmaktadır ${ }^{28-30}$.

Bifosfonatlar intravenöz veya oral yolla kullanılabilmektedirler. Intravenöz kullanım genelde metastaz gösteren tümörlerde, kanserin neden olduğu hiperkalsemide, Paget's hastalığında ve multiple myelomada tercih edilirken, oral kullanım ise osteoporoz hastalığında tercih edilir. İkinci jenerasyon olan pamidronate (Aredia) ve üçüncü jenerasyon olan zoledronic asit (Zometa) en sık kullanılan intravenöz formdaki bifosfanatlardandır. Alendronate (Fosamax), residronate (Actonel), ve ibandronate (Boniva) ise en sık kullanılan oral formdaki bifosfonatlardandır. İntravenöz bifosfonatları kullanan hastalarda spontan veya bir dentoalveolar cerrahi işleme bağlı gelişen çene kemiklerinde osteonekroz görülme olasılığı, oral olarak kullanan hastalara nazaran daha yüksektir ${ }^{31}$.

Klinik olarak çenelerde bifosfonata bağlı olarak görülen osteonekroz asemptomatik olabileceği gibi, etrafındaki dokularda enflamasyon gelişmesine bağlı olarak ağrı, şişlik, eritem ve ülserasyonlar da görülebilir (Resim 1). Bahsi geçen bu şikayetler kendiliğinden ortaya çıkabileceği gibi; yapılan diş çekimi gibi basit bir dentoalveolar işlemler sonrasında da görülebilir. Bazen diş çekimi sonrası gelişen çene osteonokrozunun klinik olarak belirti vermesi birkaç ay sürebilir. Radyolojik olarak geniş bir kemik tutulumu olmadığı sürece, çene kemiklerinin yapısında belirgin bir değişiklik gözlenmez. Dolayısıyla erken dönemde alınan panoramik veya periapikal filmler tanı koymaya yardımcı olamayabilirler. Radyolojik olarak bir görüntü 
alındığında ise bu görüntü osteomiyeliti veya kemik metastazını andırabilir (Resim 2). Bazı vakalarda periodontal aralıkta genişleme; ilerleyen zamanlarda ise bifosfanat alımının artmasıyla beraber osteosklerotik lamina dura radyolojik olarak tespit edilebilir.

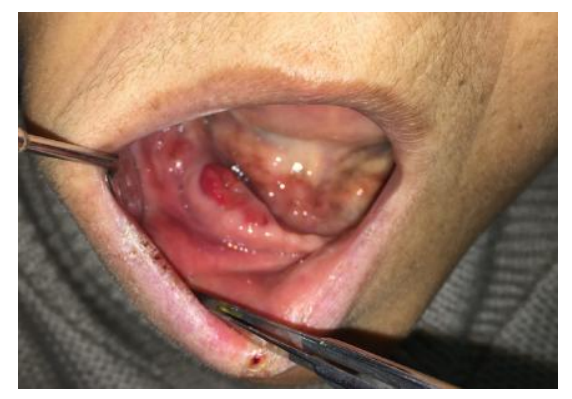

Resim 1.Mandibulanın sağında klinik olarak şişlik, ağrı ve eritem belirtileri veren BRONJ

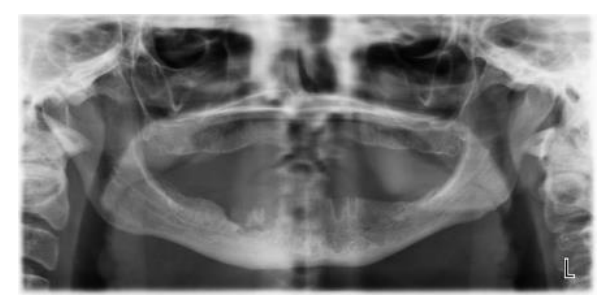

Resim 2. Mandibulanın sağında BRONJ tanısı konan hastanın panoramik filmi.

Ruggiero ve arkadaşlarının 141 hastada tedavi ettikleri bifosfonata bağlı çene osteonekroz olgularını baz alarak oluşturdukları bir evreleme mevcuttur. Buna göre bu hastalık 3 evrede sınıflandırılmıştır ${ }^{11}$.

Evre 1: Herhangi bir enflamasyon, şişlik veya eritemin olmadığı; asemptomatik olan sadece ekspoze kemiğin mevcut olduğu durum. Bu gruptaki hastalar klinik olarak ekspoze kemik görülmeden ve radyolojik olarak herhangi bir değişiklik tespit edilmeden önce geçici bir ağrıdan şikayet edebilirler. Bu evredeki hastaların tedavisinde antimikrobiyal gargaralar (\% 0.12 klorheksidinli) önerilir ve düzenli takipleri yapılır ${ }^{11}$.

Evre 2: Ekspoze kemik ile birlikte ağrının, yumuşak dokuda enflamasyona bağlı şişliğin veya ikincil bir enfeksiyonun görüldüğü vakalar bu evrededir. Evre 2'deki hasta grubunda ise antimikrobiyal gargaralara (\% 0.12 klorheksidinli) ek olarak, yapılacak antibiyogram sonucuna uygun bir antibiyotik tedavisine ve analjezik tedavisine başlanır.
Genellikle penisilin grubu antibiyotikler tedavi için yeterli olmaktadır. Evre 2 deki hastaların $\% 75^{\prime} i$ bu tedavi yöntemine olumlu cevap vermektedir ${ }^{11}$.

Evre 3: Ekspoze kemik ile birlikte ağrının, yumuşak dokuda enflamasyona bağlı şişliğin veya oral/intravenöz antibiyotik tedavisi ile kontrol altına alınması zor olan ikincil bir enfeksiyonun var olduğu vakalar bu evrededir. Bu grupta bulunan vakalarda çene osteonekrozuna bağlı ekstraoral fistül veya patolojik kırıklar sıklıkla görülebilir. Sinüs maksillaris de enfeksiyona dahil olabilir. Nekrotik kemiğin geniş hacimli olmasından dolayı, bu hastalar cerrahi olarak tedavi edilmek zorundadır. Cerrahi müdehale öncesi ve sonrasında oral veya intravenöz antibiyotik tedavisi, analjezik ve antimikrobiyal gargaralar (\% 0.12 klorheksidinli gargaralar) öneriliir ${ }^{11}$.

Bu çalışma yukarıda detaylı olarak anlatılan evrelendirmeyi kullanarak BRONJ tanısı konmuş hastaların teşhis ve tedavilerini takiben uzun dönem sonuçlarını bildirmektedir.

\section{MATERYAL METOD}

Marmara Üniversitesi, Diş Hekimliği Fakültesi, Ağız, Diş ve Çene Cerrahisi Anabilim Dalı'nda çeşitli sebeplerle bifosfonat kullanan ve BRONJ tanısı konan, ikisi erkek, altısı kadın 8 hastanın tedavileri ve takipleri yapılmışıı. Kadın hastalardan üçü osteoporoz nedeniyle, kalan hastalar ise malign tümör tanısı nedeniyle bifosfonat grubu ilaç kullanmaktadır. Hastaların 6 tanesi intravenöz, kalan 2 tanesi ise bifosfonat grubu ilacı, oral yolla kullanmaktadır. Kanser tedavisi için bifosfonat kullanan hastalarda ayırııı tanı açısından insizyonel biyopsi ile metastaz olasilığı elimine edilmiştir. Yukarıda belirtilen BRONJ evrelendirme yöntemine göre tüm hastalar evrelendirilmiş ve buna uygun tedavileri yapılmışır. Tüm hastalardan girişimsel teşhis yöntemleri ve tedavileri öncesinde yazııı ve sözlü onamları alınmıştır.

Hastalardan üçüne evre 2, beşine ise evre 3 olarak BRONJ tanısı konulmuştur. Evre 2'de bulunan ve sadece ilaç tedavisi uygulanan hastalarda ağrı, akut enfeksiyon, ekspoze kemiğin durumu gibi klinik bulgular değerlendirilmiştir. Ayrıca tüm hastaların tedavi öncesi ve sonrası radyolojik muayeneleri yapılmışır. Evre 3 hastalara ise bunlara ek olarak cerrahi tedavi uygulanmışır. Cerrahi tedavi uygulanan 5 hastanın birine mandibular parsiyel rezeksiyon,

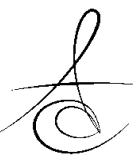


dördüne ise marginal alveolar rezeksiyon yapılmıştır. Rezeksiyon yapılan hastalara onkoloji konsültasyonu sonrası uygun görülmesi durumunda ameliyat öncesi 20 seans (2.5 ATA'da [atmosphere of air pressure absolute] 1 saat); ameliyat sonrası ise 10 seans (2.5 ATA'da 1 saat) yardımcı tedavi olarak hiperbarik oksijen tedavisi uygulanmıştır. Konsültasyonları sonucu 5 rezeksiyon hastasının üçü için hiperbarik oksijen tedavisi uygun görülmüş ve uygulanmıştı. Aynı şekilde hastalara bifosfonat tedavisi yapan hekimlerle konsülte edilerek kullanılan bifosfanatlara BRONJ tedavisi süresince ara verilmiştir. Buna ek olarak ameliyat öncesi hastalarda kanda PTH, kalsiyum, osteokalsin, Beta-CTx ve $D$ vitamini değerlerine bakılmıştır. Hastalara BRONJ tanısı öncesi ve sonrasında D vitamini taksiyesi yapılmamışıı.

Hastalar tedavileri sonrasında 4 ila 21 ay arasında değişen bir süre boyunca, 3 ayda bir klinik muayeneleri yapılmak şartıyla, ortalama 12,5 ay takip edilmişlerdir.

\section{BULGULAR}

Yaşları 48 ila 80 arasında değişen, ortalama yaşın 61.2 olduğu, ikisi erkek altısı kadın olmak üzere BRONJ tanısı konan 8 hastanın yapılan tedavileri sonrası 4-21ay arasında değişen klinik ve radyolojik takipleri yapılmışıı (Resim 3 ve 4). Sekiz hastanın dördüne maxillada, diğer kalan dördüne ise mandibulada BRONJ tanısı konulmuş ve tedavileri gerçekleştirilmiştir. Bu hastalar kliniğimize ilk başvurduklarında üçünün hastalığı evre 2 , diğer beşinin $\mathrm{ki}$ ise evre 3 olarak sınıflandırımıştır. Hastalardan alınan anamnezde sekiz hastanın üçünün bifosfonat grubu ilacı osteoporoz nedeniyle, kalan beşinin ise çeşitli kanserlerin kemik metastazını engellemek veya durdurmak amaçı kullanmakta olduğu rapor edilmiştir. Hastalardan ikisi bifosfonat grubu ilacı oral yolla almaktayken kalan altısı ise bu grup ilacı intravenöz olarak 8 ila 43 ay arasında değişen, ortalama 23.8 aylık bir zaman zarfı boyunca almaktadır. Bu hastalardan altı tanesi bifosfonat olarak zoledronic asit kullanırken, kalan iki tanesi oral yoldan ibandronate kullanmaktadır (Tablo 1). Sekiz hastanın sadece birinde spontan olarak BRONJ gelişmişken, kalan 7 hastada diş çekimi gibi minör cerrahi girişimler sonrası uzun dönemde BRONJ ortaya çıkmıştır. Spontan BRONJ gelişimi gösteren hasta, 80 yaşında osteoporoz hastası olup alt çenesinde 2. evre BRONJ tespit edilmiştir. Bu hastanın 11 sene gibi uzun bir dönem boyunca uyumu tamamen bozulmuş bir total protez kullanımı söz konusudur. Gelişen spontan BRONJ'un bu uyumu tamamen bozulmuş olan total protezle alakalı olabileceği düşünülmektedir.

Tablo 1. Çalışmaya konu olan hastaların primer hastalıkları, kullandıkları-bifosfonat grubu ilaçlar, BRONJ evreleri, tedavi ve takip süreleri.

\begin{tabular}{|c|c|c|c|c|}
\hline $\begin{array}{c}\text { Cinsiyet/ } \\
\text { Yaş }\end{array}$ & $\begin{array}{c}\text { Primer } \\
\text { Hastalık }\end{array}$ & $\begin{array}{c}\text { Bifosfonat/ } \\
\text { Kullanım } \\
\text { Yolu/Dozu } \\
\text { /Süresi }\end{array}$ & $\begin{array}{c}\text { BRONJ Evre/ } \\
\text { Lokasyon/ } \\
\text { Tedavi }\end{array}$ & $\begin{array}{l}\text { Takip } \\
\text { Süresi }\end{array}$ \\
\hline $\begin{array}{c}\text { Erkek } \\
\text { /54 }\end{array}$ & $\begin{array}{c}\text { Multiple } \\
\text { Myeloma }\end{array}$ & $\begin{array}{c}\text { Zoledronic } \\
\text { asit/IV/Ayda } \\
\text { bir doz/18 ay }\end{array}$ & $\begin{array}{c}\text { Evre } 3 / \text { Maxilla/ } \\
\text { Marjinal } \\
\text { rezeksiyon }\end{array}$ & 9 ay \\
\hline $\begin{array}{c}\text { Kadın/ } \\
70\end{array}$ & $\begin{array}{l}\text { Osteopo } \\
\text { roz }\end{array}$ & $\begin{array}{l}\text { İbandronate/ } \\
\text { Oral/Haftada } \\
\text { bir doz/31 ay }\end{array}$ & $\begin{array}{c}\text { Evre } 3 / \text { Maxilla/ } \\
\text { Marjinal } \\
\text { rezeksiyon }\end{array}$ & 12 ay \\
\hline $\begin{array}{c}\text { Kadın/ } \\
80\end{array}$ & $\begin{array}{l}\text { Osteopo } \\
\text { roz }\end{array}$ & $\begin{array}{c}\text { Zoledronic } \\
\text { asit/IV/Ayda } \\
\text { bir doz/23 ay }\end{array}$ & $\begin{array}{c}\text { Evre 2/ } \\
\text { Mandibula/ } \\
\text { İlaç tedavisi }\end{array}$ & 16 ay \\
\hline $\begin{array}{l}\text { Kadın/ } \\
56\end{array}$ & Renal Ca & $\begin{array}{c}\text { Zoledronic } \\
\text { asit/IV/Ayda } \\
\text { bir doz/43 ay }\end{array}$ & $\begin{array}{c}\text { Evre 3/ } \\
\text { Mandibula/ } \\
\text { Segmental } \\
\text { rezeksiyon } \\
\text { Hiperbarik }\end{array}$ & 14 ay \\
\hline $\begin{array}{c}\text { Kadın/ } \\
49\end{array}$ & $\begin{array}{c}\text { Akciğer } \\
\text { Ca }\end{array}$ & $\begin{array}{c}\text { Zoledronic } \\
\text { asit/IV/Ayda } \\
\text { bir doz/18 ay }\end{array}$ & $\begin{array}{c}\text { Evre 3/ } \\
\text { Mandibula/ } \\
\text { Marjinal } \\
\text { rezeksiyon } \\
\text { Hiperbarik }\end{array}$ & 21 ay \\
\hline $\begin{array}{c}\text { Kadın/ } \\
77\end{array}$ & $\begin{array}{l}\text { Osteopo } \\
\text { roz }\end{array}$ & $\begin{array}{l}\text { İbandronate/ } \\
\text { Oral/Haftada } \\
\text { bir doz/35 ay }\end{array}$ & $\begin{array}{l}\text { Evre 2/ Maxilla/ } \\
\text { İlaç tedavisi }\end{array}$ & 9 ay \\
\hline $\begin{array}{c}\text { Kadın/ } \\
48\end{array}$ & Renal Ca & $\begin{array}{c}\text { Zoledronic } \\
\text { asit/IV/Ayda } \\
\text { bir doz/8 ay }\end{array}$ & $\begin{array}{c}\text { Evre 3/ Maxilla/ } \\
\text { Marjinal } \\
\text { rezeksiyon } \\
\text { Hiperbarik }\end{array}$ & 4 ay \\
\hline $\begin{array}{c}\text { Erkek/ } \\
56\end{array}$ & $\begin{array}{c}\text { Prostat } \\
\text { Ca }\end{array}$ & $\begin{array}{c}\text { Zoledronic } \\
\text { asit/IV/Ayda } \\
\text { bir doz/15 ay }\end{array}$ & $\begin{array}{c}\text { Evre 2/ } \\
\text { Mandibula/ } \\
\text { İlaç tedavisi }\end{array}$ & 15 ay \\
\hline
\end{tabular}

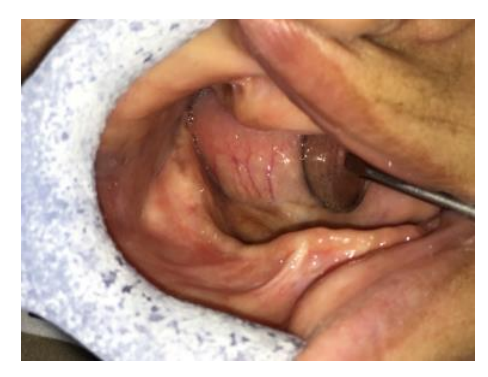

Resim 3. Resim 2 deki hastanın ameliyat sonrası klinik görüntüsü. 


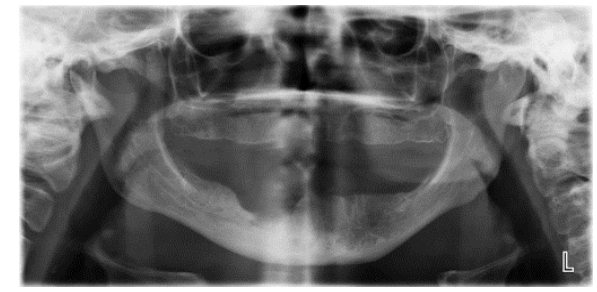

Resim 4. Resim 2 deki hastanın ameliyat sonrası panoramik film görüntüsü.

Üçüncü evrede kliniğimize başvuran ve ameliyat edilen 5 hastanın tamamında takip süreleri boyunca tekrarlayan bir BRONJ olgusu görülmemiştir. Kalan 3 tane ikinci evre BRONJ hastasında ise uygulanan ilaç tedavi protokolü ile hastalık semptomatik olarak kontrol altında tutulabilmiş ve hastalığın klinik ve radyolojik olarak herhangi bir ilerleme göstermediği görülmüştür. Operasyon öncesi ve sonrasında hiperbarik oksijen tedavisi gören 3 hastanın hiçbirinde bu tedaviye bağlı herhangi bir komplikasyon gözlenmemiştir. Ameliyat edilen 5 hastanın kanda ölçülen PTH, kasiyum, osteokalsin, Beta-CTx ve vitamin $D$ ortalama değerleri sırasıyla $107.7 \mathrm{pg} / \mathrm{ml}, 9.4 \mathrm{mg} / \mathrm{dl}, 10 \mathrm{ng} / \mathrm{ml}, 0.224 \mathrm{ng} / \mathrm{ml}$ ve 118 $\mathrm{pg} / \mathrm{ml}$ olarak belirlenmiştir. Ortalama PTH, kalsiyum, ve $D$ vitamini değerleri normal sınırların üstündeyken, osteokalsin ve Beta-CTx değerleri normal sınırların altında kalmıştır (Tablo 2).

Tablo 2. Ameliyat edilen hastaların ameliyat öncesi PTH, Ca, Osteokalsin, Beta-CTx ve Vitamin D değerleri

\begin{tabular}{|c|c|c|c|c|c|c|}
\hline $\begin{array}{l}\text { Cinsiyet } \\
\text { I } \\
\text { Yaş }\end{array}$ & \begin{tabular}{|c|} 
Primer \\
Hastalık
\end{tabular} & $\begin{array}{l}\text { PTH } \\
(18.5- \\
88 \mathrm{pg} / \\
\mathrm{ml})\end{array}$ & \begin{tabular}{|l|} 
Kalsiyu \\
$\mathrm{m}(8.5-$ \\
10.1 \\
$\mathrm{mg} / \mathrm{dl})$
\end{tabular} & $\begin{array}{l}\text { Osteokalsi } \\
\text { n } \\
(11-46 \\
\text { ng/ml) }\end{array}$ & $\begin{array}{l}\text { Beta- } \\
\text { CTx } \\
(0.590 \\
-1.00 \\
\text { ng/ } \\
\mathrm{ml})\end{array}$ & $\begin{array}{l}\text { Vitami } \\
\text { n D } \\
(26.1- \\
95 \mathrm{pg} / \\
\mathrm{ml})\end{array}$ \\
\hline $\begin{array}{c}\text { Erkek/ } \\
54\end{array}$ & \begin{tabular}{c|} 
Multiple \\
Myeloma \\
\end{tabular} & 132 & 9.14 & 9.65 & 0.203 & 144 \\
\hline $\begin{array}{l}\text { Kadın/ } \\
70\end{array}$ & Osteoporoz & 65 & 10.61 & 13.43 & 0.156 & 81 \\
\hline $\begin{array}{c}\text { Kadın/ } \\
56\end{array}$ & Renal $\mathrm{Ca}$ & 124 & 8.80 & 10.25 & 0.232 & 121 \\
\hline $\begin{array}{c}\text { Kadın/ } \\
49\end{array}$ & Akciğer Ca & 73.5 & 9.63 & 9.23 & 0.287 & 92 \\
\hline $\begin{array}{c}\text { Kadın/ } \\
48\end{array}$ & Renal Ca & 144 & 8.90 & 7.39 & 0.246 & 152 \\
\hline
\end{tabular}

Bu çalışmaya dahil edilen 8 hastaya hastalıklarının akut dönemlerinde intravenöz yolla penisilin (ampicilin 1gr) tedavisi uygulanmış; daha sonra ameliyat olan hastalara da postoperatif olarak metronidazol ve azitromisin kombinasyonu oral antibiyotik tedavisi uygulanmışır. Tüm hastalar tedavileri boyunca klorheksidin gargara kullanmıştır.
BRONJ tedavisinde doğru antibiyotik kullanımı tedavinin başarııını direk olarak etkilemektedir. Tüm hastalar uygulanan antibiyotik tedavisine cevap vermiş ve ek bir antibiyotik kullanımına gerek kalmamışır.

\section{TARTIŞMA}

Bifosfonatlar veya antianjiogenik ilaçlar çene kemiklerinde spontan veya diş çekimi gibi yapılan basit bir cerrahi işlem sonrasında osteonekroza neden olabilirler. Bu ilaçların kullanım süresi ve şekli, ilacın tipi, hastanın dentoalveolar işlem görüp görmemesi ve ağızda mevcut hareketli bir protezin bulunup bulunmaması potansiyel risk faktörleri arasında sayılabilir. Bu risk faktörleri arasında en önde yer alanı ise ilacın kullanımına başlandıktan sonra yapılan bir cerrahi dentoalveolar müdahale gelmektedir. Bu çalışmanın konusu olan 8 hastanın risk faktörleri bu bilgiyi doğrular niteliktedir çünkü hastaların yedisinde BRONJ dentoalveolar girişimler sonrasında, birinde ise uyumu kötü hareketli protez kullanımına bağlı ortaya çıkmıştır. Dolayısıyla diş hekimleri hastalarından detaylı anamnez almalı, bu ilaçların yan etkilerinden haberdar olmalı ve bu grup ilaç kullanan hastalarda daha dikkatli olmalıırlar. ${ }^{32,33}$ Bifosfonatlar veya antianjiogenik kullanan hastalarda eğer restore edilemeyecek kadar çürük bir diş varsa, dişin kron kısmının alınıp kök kısmına kanal tedavisi yapmak diş çekiminden çok daha uygun olacaktır. Tüm bu verilerin ışığı altında bifosfonatlar veya antianjiogenik ilaç kullanımı dentoalveolar cerrahi işlemler açısından kesin bir kontraendikasyon oluşturmamakla birlikte; bu grup hastaların potansiyel oluşabilecek osteonekroz riski konusunda tam olarak bilgilendirilmeleri gerekmektedir. ${ }^{11}$ Eğer bir hastada bifosfonat veya antianjiogenik ilaç kullanımına başlanacaksa öncelikle tüm dental tedavilerin yapılması ve prognozu kötü olabilecek dişlerin önceden çekimi önerilir. Diş tedavileri tamamlandiktan en az 4-6 hafta sonra bifosfonat veya antianjiogenik ilaç tedavisine başlanmalıdır. Parsiyel veya total protez kullanan hastalar ise rutin olarak vuruk açısından kontrol edilmelidir. Bifosfonatlar veya antianjiogenik ilaçları kullanan ve çene kemiklerinde osteonekroz bulunmayan hastalarda ise konservatif dental tedaviler önerilirken rutin 6 aylık kontrolleri yapılmalıdır.

Özellikle pamidronate ve zolendronate gibi bifosfonatları intravenöz olarak kullanan hastaların

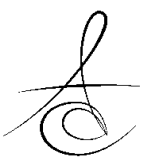


çene kemiklerinde spontan osteonekrotik alanların oluşma riski oral bifosfonat kullanan hastalara göre daha fazladır. ${ }^{34}$ Bizim hasta grubumuzda da altı hasta intravenöz olarak zolendronik asit kullanırken, sadece iki hasta oral olarak ibandronate kullanmaktadır. Konuyla ilgili günümüze kadar yapılmış çalışmalara bakıldığında bifosfanat kullanımına bağı görülen BRONJ oranı oral kullanımlarda $\% 0.01$ ile \%0.06; intranevöz kullanımlarda ise \%0.8 ile \%12 arasındadır. ${ }^{35,36-38}$ Yapılan bir çalışmaya göre ise meme kanseri nedeniyle intravenöz yolla bifosfonat kullanan hastaların \%4.3ünde; multiple myeloma nedeniyle bifosfonat kullanan hastaların ise \%6.9 unda spontan olarak çene kemiklerinde osteonekroz gelişmiştir. ${ }^{34} \mathrm{Bu}$ çalışmada da osteoporoz nedeniyle intravenöz yolla zoledronic asit alan sadece bir hastada spontan olarak BRONJ görülmüş ve tedavi edilmiştir. Konuyla ilgili literatür ve çalışmamızın sonuçları intravenöz bifosfonat kullanımının oral kullanıma göre BRONJ görülme riski bakımından çok daha riskli olduğunu göstermiştir.

Ruggiero ve arkadaşlarının yapmış olduğu BRONJ evrelemesi günümüzde hala geçerliliğini devam ettirmektedir. ${ }^{11}$ Evre 1 vakalarını tespit etmek oldukça güçtür çünkü hastalığın klinik belirtileri henüz tam olarak görülmemektedir. Bu yüzden anamnezinde bifosfonat grubu ilaç kullanımı olan hastalar rutin ağız muayeneleri esnasında ekspoze çene kemiğinin var olup olmadığı bakımından değerlendirilmelidirler. Bu çalışmada ikinci evredeki üç hastanın tamamı ilaç tedavisine cevap vermiş ve ağrı, akut enfeksiyon gibi şikayetleri geçmiştir. Fakat ağız içinde ekspoze çene kemiği varlığı devam etmiştir. Bu durum kabul edilebilir bir durumdur. Ama unutulmamalıdır ki tedavi edilmiş evre 2 vakalarının her an evre 3 BRONJ'a dönüşme riskleri ardır. Dolayısıyla düzenli takipleri şarttır.

Açlık serum C-terminal telopeptit (Beta-CTx) kemikte bulunan tip I kollajenin yıkımıyla ortaya çıkan, kemik döngüsünü gösteren biyolojik bir göstergedir. Kemik döngüsünün baskılanmasıyla beraber kandaki Beta-CTx seviyesi düşer. ${ }^{39}$ Buna istinaden Beta-CTx değerinin BRONJ riskini belirlemede etkili olduğunu söyleyen çalışmalar vardır. ${ }^{8,40-42}$ Bu çalışmalara göre Beta-CTx seviyesinin $150 \mathrm{pg} / \mathrm{ml}$ ve üstünde olduğu durumlarda BRONJ riskinin düşük, 100-150 pg/ml aralığında orta, $100 \mathrm{pg} / \mathrm{ml}$ ve altında ise yüksek olduğunu bildirilmiştir. ${ }^{40,43,44}$ Bizim bu çalışmamıza dahil ettiğimiz tüm hastaların Beta-CTx değerleri 150 $\mathrm{pg} / \mathrm{ml}$ 'nin üstündedir. Fakat bazı çalışmalar ise BetaCTx değerinin bir anlam ifade etmediğini ileri sürer. ${ }^{39,45,46}$ Bifosfanat kullanan hastalarda oral cerrahi işlemler öncesinde ölçülen Beta-CTx değeri BRONJ riskini kesin olarak ortaya koymasa da, klinik olarak postoperatif prognozun nasıl olabileceği hakkında ve işlem öncesi ilaç tatili verilip verilmemesi konusunda bir fikir verebilir. ${ }^{45}$

Yapılan bazı çalışmalarda BRONJ hastalarında bifosfonat grubu ilaca ara verilerek sadece hiperbarik oksijen tedavileri sonrası hastalıkta gerileme ve iyileşme yönünde ilerleme hastaların $\% 62.5^{\prime}$ inde tespit edilmiştir. ${ }^{47-49}$ Bifosfonat tedavisine ara vermek hiperbarik oksijen tedavisinin başarısını önemli oranda arttırmaktadır. ${ }^{50}$ Dolayısıyla bu çalışmaya dahil edilen hastalara, hekimleri ile konsülte ettikten sonra, bifosfonat tedavisine en az 3 ay ara verdirilmiş ve uygun hastalara hiperbarik oksijen tedavisi uygulanmıştır. $\mathrm{Bu}$ tedavi protokolünün BRONJ vakalarını tedavi etmede önemli bir yerinin olduğunu düşünmekteyiz.

Bifosfonatlar veya antianjiogenik ilaçları kullanan ve çene kemiklerinde osteonekroz bulunan hastalarda panoramik ve tomografi görüntüleme yöntemlerine başvurulmalıdır. Mikrobiyal kültür sonucuna göre uygun antibiyotik tedavisine başlanmalıdır. $\mathrm{Bu}$ çalışmaya dahil edilen hastalarda olduğu gibi penisilin veya metronidazol ve azitromisin kombinasyonu en uygun antibiyotik seçimi olacaktır. ${ }^{51}$ Semptomatik BRONJ hastalarının tedavilerini düzenlemek oldukça güç olabilir. Bunun başlıca nedeni bu hasta grubunun cerrahi tedavilere ne tür cevap vereceklerini önceden tahmin etmek oldukça güç olmasıdır. Bazı hastalarda cerrahi debridmana ek olarak hiperbarik oksijen tedavisi yapılmış olsa bile hastalık kontrol altına alınamayabilir. ${ }^{37,38}$ Buna ek olarak cerrahi sınırları belirlemek de oldukça güçtür çünkü tüm çene kemiği kullanılan ilaca maruz kalmış ve ilacın etkisi altındadır.

\section{SONUÇ}

Bu çalışmada kullanılan BRONJ sınıflamasına sağdık kalınarak, cerrahi tedavinin veya ilaç tedavisinin gerektiğinde uygun zamanda yapılması başarılı sonuç elde etmek açısından önemlidir. Bifosfonat kullanım nedenleri hastaların cerrahi ya da medikal yolla tedavi edilmelerinde direkt olarak etkili olmamıştır. Ayrıca 
BRONJ tedavisinde hiperbarik oksijen tedavisi yardımcı tedavi olarak düşünülmelidir.

Necip FazIl Erdem : ORCID ID: 0000-0002-5374-3233 Zeynep Gümüşer: ORCID ID: 0000-0002-7834-4343

\section{KAYNAKLAR}

1-Ruggiero SL, Dodson TB, Fantasia J, Goodday R, Aghaloo T, Mehrotra B. American association of oral and maxillofacial surgeons position paper on medication-related osteonecrosis of the jaw-2014 update. J Oral Maxillofac Surg 2014;72:1938-56.

2-Wood J, Bonjean K, Ruetz S, Ballahcene A, Devy L, Foidart JM. Novel antiangiogenic effects of the bisphosphonate compound zoledronic acid. J Pharmacol Exp Ther 2002;302:1055-61.

3- Santini D, Vincenzi B, Avvisati G, Dicuonzo G, Salerno A, Denaro V. Pamidronate Induces modifications of circulating angiogenic factors in cancer patients. Clin Cancer Res 2002; 8:1080-4.

4-Calvani F, Cutone A, Lepanto MS, Rosa L, Valantini V, Valenti P. Efficacy of bovine lactoferrin in the post-surgical treatment of patients suffering from bisphosphonate-related osteonecrosis of the jaws: an open-label study. Biometals 2018;doi: 10.1007/s10534-018-0081-y. Basım aşamasında.

5-Bone HG, Hosking D, Devogelsaer J-P, Tucci JR, Emky RD, Tonino RP. Ten years' experience with alendronate for osteoporosis in postmenopausal women. N Engl J Med 2004;350:1189-99.

6-Reid IR, Miller P, Lyles K, Fraser W, Brown JP, Saidi $Y$. Comparison of a single infusion of zoledronic acid with risedronate for paget's disease. $\mathrm{N}$ Engl J Med 2005;353:898-908.

7. Deftos $\amalg$. treatment of paget's disease-taming the wild osteoclasts. N Engl J Med 2005;353:872-5.

8. Çapar GD, Cabbar F, Yalçın M, Tomruk CÖ. İlaçlara bağlı çene osteonekrozu: derleme. Atatürk Üniv Diş Hek Fak Derg 2015;13:118-29.

9- Coello-Suanzes JA, Rollon-Ugalde V, CastanoSeiquer A, Lledo-Villar E, Herce-Lopez J, InfanteCossio P, Rollon-Mayordomo A. preventive dental management of osteonecrosis of the jaws related to zoledronic acid treatment. Oral Dis. 2018; doi: 10.1111/odi.12842. Basım aşamasında.

10- Marx RE: Pamidronate (Aredia)- and zoledronate (zometa)-induced avascular necrosis of the jaws: a growing epidemic. J Oral Maxillofac Surg 2003;61:1115-7.

11- Ruggiero SL, Fantasia J, Carlson E. bisphosphonate- related osteonecrosis of the jaw: background and guidelines for diagnosis, staging and management. Oral Surg Oral Med Oral Pathol Oral Radiol Endod 2006;102:433-40.

12-Mehrotra B, Fantasia J, Nissel-Horowitz S, Vinarsky S, Ruggiero S. osteonecrosis of the maxilla: an unusual complication of prolonged bisphosphonate therapy. a case report. Proc Am Soc Clin Oncol 2003;22:795.

13-Migliorati CA. bisphosphonates and oral cavity avascular bone necrosis. J Clin Oncol 2003;21:4253-4.

14-Yasuda $\mathrm{H}$, Shima N, Nakagawa N. osteoclast differentiation factor is a ligand for osteoprotegerin/ osteoclastogenesis-inhibitory factor and is identical to TRANCE/RANKL. Proc Natl Acad Sci 1998;95:3597-602.

15- Lacey DL, Timms E, Tan HL. Osteoprotegerin Ligand is a Cytokine that regulates osteoclast differentiation and activation. Cell 1998;93:16576.

16- Tsuda E, Goto M, Mochizuki S, Yano K, Kobayashi $\mathrm{F}$, Morinaga $\mathrm{T}$, Higashio $\mathrm{K}$. Isolation of a novel cytokine from human fibroblasts that specifically Inhibits osteoclastogenesis. Biochem Biophys Res Commun 1997;234:137-42.

17- Simonet WS, Lacey DL, Dunstan CR. Osteoprotegerin: A novel secreted protein Involved in the regulation of bone density. Cell 1997;89:309-9.

18- Suda T, Takahashi N, Udagawa N, Jimi E, Gillespie MT, Martin TJ. Modulation of osteoclast differentiation and function by the new members of the tumor necrosis factor receptor and ligand families. Endocr Rev 1999;20:345-357.

19- Jimi E, Furuta H, Matsuo K, Tominaga K, Takahashi T, Nakanishi $O$. The cellular and molecular mechanisms of bone invasion by oral squamous cell carcinoma. Oral Diseases 2011;17:462-8.

20- Shin M, Matsuo K, Tada T, Fukushima H, Furuta $H$, Ozeki S, Kadowaki T, Yamamoto K, Okamoto M, Jimi E. The Inhibition of RANKL/RANK signaling by osteoprotegerin suppresses bone invasion by oral 
squamous cell carcinoma cells. Carcinogenesis 2011;32: 1634-40.

21- Martin CK, Dirksen WP, Carlton MM, Lanigan LG, Pillai SP, Werbeck JL, Simmons JK, Hildreth III BE, London CA, Toribio RE, Rosol TJ. Combined zoledronic acid and metoxicam reduced bone loss and tumour growth in an orthotopic mouse model of bone-ınvasive oral squamous cell carcinoma. Veterinary and Comparative Oncology 2015;13:203-17.

22- Patel V, Mansi J, Ghosh S, Kwok J, Burke M, Reilly D, Nizarali N, Sproat C, Chia K. MRONJ Risk of adjuvant bisphosphonates in early stage breast cancer. . Br Dent J 2018;224:74-79.

23- Müller $\mathrm{H}$, Slootweg PJ. Mandibular Invasion by oral squamous cell carcinoma. clinical aspects. J Craniomaxillofac Surg 1990;18:80-4.

24- Totsuka Y, Usui Y, Tei K, Kida M, Mizukoshi T, Notani K, Fukuda H. Results of surgical treatment for squamous carcinoma of the lower alveolus: segmental vs. marginal resection. Head Neck 1991;13:114-20.

25- Wong RJ, Keel SB, Glynn RJ, Varvares MA. Histological pattern of mandibular Invasion by oral squamous cell carcinoma. Laryngoscope 2000;110:65-72.

26- Guise TA, Mundy GR. Cancer and bone. Endocr Rev 1998;19:18-54.

27- Takayama Y, Mori T, Nomura T, Shibahara T, Sakamoto M. Parathroid-related protein plays a critical role in bone invasion by oral squamous cell carcinoma. Int J Onco 2010;36:1387-94.

28-- Ha H, Kwak HB, Lee SW. Reactive oxygen species mediate rank signaling in osteoclasts. Exp Cell Res 2004;301:119-27.

29. Lee NK, Choi YG, Baik JY. A Crucial role for reactive oxygen species in RANKL-induced osteoclast differentiation. Blood 2005;106:852-9.

30. Reddy SV. Regulatory mechanisms operative in osteoclasts. Crit Rev Eukaryot Gene Expr 2004; 14:255-70.

31- Berenson JR, Hillner BE, Kyle RA, Anderson K, Lipton A, Yee GC, Biermann JS. American society of clinical oncology clinical practice guidelines: the role of bisphosphonates in multiple myeloma. J Clin Oncol 2002;20:3719-36.
32- Dimopoulos M, Kastritis E, Moulopoulos LA, Melakopoulos I, Anagnostopoulos A, Gika D. The Incidence of Osteonecrosis of the Jaw in Patients with Multiple Myeloma who Receive Bisphosphonates Depends on the Type of Bisphosphonate. Blood 2005;106:Abstract \#637

33- Migliorati CA, Casiglia J, Epstein J, Siegel, MA, Woo SB. Managing the Care of Patients with Bisphosphonate-Associated Osteonecrosis. JADA 2005;136:1658-68.

34- Durie BGM, Katz M, Crowley J. Osteonecrosis of the Jaw and Bisphosphonates. N Engl J Med 2005;353:99.

35- Dal Pra' KJ, Lemos CAA, Okamoto R, Soubhia AMP, Pellizzer E. Efficacy of the C-terminal Telopeptide Test in Predicting the Development of Bisphosphonate-related Osteonecrosis of the Jaw: A Systematic Review. Int J Oral Maxillofac Surg 2017;46:151-6.

36- Beninati F, Pruneti R, Ficarra G. Bisphosphonaterelated Osteonecrosis of the Jaws (BRONJ). Med Oral Patol Oral Cir Bucal 2013;18:e752-8.

37- Ruggiero SL, Mehrotra B, Rosenberg TJ, Engroff S. Osteonecrosis of the Jaws Associated with the Use of Bisphosphonates: A Review of 63 Cases. J Oral Maxillofac Surg 2004;62:527-34.

38- Marx RE, Sawatari Y, Fortin M, Broumand V. Bisphosphonate Induced Exposed Bone (osteonecrosis/osteopetrosis) of the Jaws: Risk Factors, Recognition, Prevention and Treatment. J Oral Maxillofac Surg 2005;63:1567-75.

39- Lee CY, Suzuki JB. CTX Biochemical Marker of Bone Metabolism. Is It a Reliable Predictor of Bisphosphonate-associated Osteonecrosis of the Jaws After Surgery? Part I: Biological Concepts with a Review of the Literature. Implant Dent 2009;18:492-500.

40- Marx RE, Cillo JE, Ulloa JJ. Oral bisphosphonateinduced osteonecrosis: risk factors, prediction of risk using serum ctx testing, prevention, and treatment. J Oral Maxillofac Surg 2007;65:2397410.

41-Kwon YD, Kim DY, Ohe JY, Yoo JY, Walter C. correlation between serum c-terminal cross-linking telopeptide of type I collagen and staging of oral bisphosphonate-related osteonecrosis of the jaws. J Oral Maxillofac Surg 2009;67:2644-8. 
42. Kwon YD, Ohe JY, Kim DY, Chung DJ, Park YD. Retrospective study of two biochemical markers for the risk assessment of oral bisphosphonate-related osteonecrosis of the jaws: can they be utilized as risk markers? Clin Oral Implants Res 2011;22:1005.

43-Flichy-Fernandez AJ, Gonzalez-Lemonnier S, Balaguer-Martinez J, Penarrocha-Oltra D, Penarrocha-Diago MA, Bagan-Sebastian JV. bone necrosis around dental Implants: a patient treated with oral bisphosphonates, drug holiday and no risk according to serum CTX. J Clin Exp Dent 2012; 4:e82-5.

44. Friedlander $\mathrm{AH}$, Chang $\mathrm{TI}$, Hazboun RC, Garrett NR. High c-terminal cross-linking telopeptide levels are associated with a minimal risk of osteonecrosis of the jaws in patients taking oral bisphosphonates and having exodontia. J Oral Maxillofac Surg 2015;73:1735-40.

45- Hutcheson A, Cheng A, Kunchar R, Stein B, Sambrook P, Goss A. A c-terminal cross-linking telopeptide test based protocol for patients on oral bisphosphonates requiring extraction: a prospective single center controlled study. J Oral Maxillofac Surg 2014;72:1456-62.

46. Migliorati CA, Saunders D, Conlon MS, Ingstad HK, Vaagen $\mathrm{P}$, Palazzolo MJ. Assessing the association between bisphosphonate exposure and delayed mucosal healing after tooth extraction. J Am Dent Assoc 2013;144:406-14.

47-Landesberg R, Wilson T, Grbic JT. Bisphosphonateassociated Osteonecrosis of the Jaw: conclusions based on an analysis of case series. Dent Today 2006;25:52,54-7.

48-Mignogna MD, Fedele S, Lo Russo L. Case 2: osteonecrosis of the jaws associated with bisphosphonate therapy. J Clin Oncol 2006;24:1475-77.

49- Soileau KM. Oral post-surgical complications following the administration of bisphosphonates given for osteopenia related to malignancy. J Periodontol 2006;77:738-43.

50- Freiberger JJ, Padilla-Burgos R, Chhoeu AH, Kraft $\mathrm{KH}$, Boneta O, Moon RE, Piantadosi CA. Hyperbaric oxygen treatment and bisphosphonate-ınduced osteonecrosis of the jaw: a case series. J Oral Maxillofac Surg 2007;65:1321-27.
51- Bermúdez-Bejarano EB, Serrera-Figallo MA, Gutiérrez-Corrales A, Romero-Ruiz MM, Castillo-deOyagüe R, Gutiérrez-Pérez JL, Torres-Lagares D. Prophylaxis and antibiotic therapy in management protocols of patients treated with oral and Intravenous bisphosphonates. J Clin Exp Dent 2017;9:e141-9.

\section{Yazışma Adresi}

Dr. Öğr. Üyesi Necip Fazıl ERDEM

Marmara Üniversitesi

Dişhekimliği Fakültesi,

Başıbüyük Sağlık Yerleşkesi, Başıbüyük Yolu 9/3

Başıbüyük / Maltepe / İstanbul e-mail: nferdem@yahoo.com 